\title{
DECOLORISATION OF METHYLENE BLUE OVER TITANIA-BASED CATALYSTS: THE INFLUENCE OF DIFFERENT PH VALUES USED IN THE CATALYST PREPARATION PROCEDURE
}

\author{
Marija B. Vasić, Aleksandra R. Zarubica*
}

(ORIGINAL SCIENTIFIC PAPER)

University of Niš, Faculty of Science and Mathematics, Department of Chemistry, Niš, Serbia UDC 549.514:66.097:667.289

In this study, nano-sized $\mathrm{TiO}_{2}$-based powders were synthesized by a modified solgel method. The influence of $\mathrm{pH}$ values of the precursor solution during the synthesis process on textural, structural and morphological properties of the titania-based catalysts was investigated. Photocatalytic activity of the prepared titania samples was tested by decolorisation/degradation of Methylene blue (MB) as a model pollutant under UV-A illumination. Finally, in order to optimize the photocatalytic process, the influence of the initial MB dye concentrations was also observed with the use of the catalyst sample synthesized at $\mathrm{pH} 10$. The obtained results indicated a greater effect of the dye decolorisation when the catalyst prepared at $\mathrm{pH} 10$ was used, compared with the catalyst prepared at $\mathrm{pH} 13$. The photocatalytic activity was correlated with physico-chemical properties of the synthesized materials.
Keywords: Methylene blue, Nano-sized powders, $\mathrm{pH}$ value, Sol-gel, Titania

\section{Introduction}

In textile, paper and other industries, a great amount of waste water is generated, and its purification before it is released into the environment is essential. This water contains a large amount of dyes. Among, Methylene blue is widely present due to its high application in textile industries and in a variety of other applications [1]. Methylene blue (it has a heteropolyaromatic structure) is a cationic dye that can be very harmful for the aquatic life and humans, and can cause both environmental and health problems $[2,3]$. If inhaled, it can cause breathing difficulties and if ingested it can cause nausea, diarrhea, vomiting, headache, mental confusion, painful micturition and methemoglobinemia-like syndromes [1].

The conventional physical, chemical and biological treatments (adsorption, coagulation, filtration, sedimentation etc.) prove to be insufficient for the removal and/ or destruction of organic pollutants, since they often imply transferring pollutants from one phase to the other and/or can result in the secondary pollution $[4,5]$. In this contest, when the removal of resistant organic pollutants from water is required [2], a heterogeneous catalysis has found a wide application. A commonly used catalyst for this purpose is titania due to its numerous favorable properties. Titania is considered to be very effective in terms of both ecological and economical aspects. It is inexpensive, commercially available, chemically stable, non-toxic and has a long-term photo-stability $[5,6]$.
Several techniques have been employed for the nano-size titania preparation including the hydrothermal method [7], sol-gel [8], a solvo-thermal technique [9], precipitation [10], electro-chemical methods etc. [11]. The sol-gel process is recognized as an efficient way of obtaining nano-size titania materials with high homogeneity and desired properties due to its versatility of the processing procedure [12]. The operating parameters/ preparative experimental conditions such as the synthesis procedure, a selected precursor, $\mathrm{pH}$ value during the synthesis process and the calcination temperature are crucial parameters that determine physico-chemical properties of the material [13]. There are only few reports dealing with the influence of $\mathrm{pH}$ values of the titania precursor solution/titania suspension on photocatalytic characteristics of the obtained material with respect to the photocatalytic activity.

In this paper, titania based materials were synthesized by the modified sol-gel technique, and the influence of the $\mathrm{pH}$ value of the titania precursor solution, precisely, the $\mathrm{pH}$ value of $\mathrm{TiO}_{2}$ suspension during the sol-gel procedure on physico-chemical properties was observed. For the purpose of investigating the photocatalytic activity of the synthesized catalysts, the reaction of Methylene blue (MB) decolorisation/degradation was used. Moreover, the impact of the initial dye concentration on the photocatalytic performance was also observed.

\footnotetext{
*Author address: Aleksandra Zarubica, University of Niš, Faculty of Science and Mathematics, Department of Chemistry, Višegradska 33, 18000 Niš, Serbia

E-mail: zarubica2000@yahoo.com

The manuscript received: Jun, 24, 2016.

Paper accepted: July, 21, 2016.
} 


\section{Experimental part}

Synthesis of $\mathrm{TiO}_{2}$-based nano-powders

Two types of catalysts based on $\mathrm{TiO}_{2}$ were synthesized by a modified sol-gel technique using titanium(IV)isopropoxide (Aldrich Co.) as a precursor. Firstly, two solutions were made as follows: the first solution was made by calculating the amount of titanium(IV)-isopropoxide and dissolving it in 2-propanol under inert conditions. The second solution was made by mixing water and 2-propanol, and was added to the first one drop by drop under vigorous stirring in the nitrogen atmosphere for one hour. The amount of the water was calculated so the molar ratio $\mathrm{Ti}: \mathrm{H}_{2} \mathrm{O}$ was 1:6. The $\mathrm{pH}$ value of the mixed solutions and the resulting suspension was adjusted with the $\mathrm{NaOH}$ solution to two different values of 10 and 13. The obtained precipitates were filtered, washed with distilled water and finally with the mixture of isopropanol and water in volume ratio $1: 1$. After that, both powder samples were dried at $110^{\circ} \mathrm{C}$ for $3 \mathrm{~h}$ and then calcined for $3 \mathrm{~h}$ at the temperature of $450{ }^{\circ} \mathrm{C}$. Both catalytic samples were heated to the desired temperature at a heating rate of $10{ }^{\circ} \mathrm{C} / \mathrm{min}$. In this manner, two types of catalysts were obtained denoted as: TA10 and TA13. TA stands for titania-based material, and X-number is related to the used $\mathrm{pH}$ value during the preparation procedure.

\section{Catalysts characterization}

Brunauer-Emmett-Teller (BET) surface area measurements were performed on a Micromeritics ASAP 2010 based on the adsorption/desorption of liquid nitrogen at the appropriate temperature and pressure $\left(L_{T N N_{2}} A D\right)$, with the use of $\mathrm{He}$ as a carrier gas in order to determine a specific surface area, a pore volume and a mean pore diameter/pore size of the catalysts (TA10 and TA13). Mean pore diameters and pore volumes were defined by using Barrett-Joyner-Halenda (BJH) method. Prior to the measurement, all powder samples were degassed.

The crystallographic analysis was carried out on a Philips APD-1700 diffractometer using $\mathrm{Cu}$-anticathode and monochromator, in the operating mode of $40 \mathrm{kV}$ and $55 \mathrm{~mA}$. The data were collected in the scan range of $2 \theta$ angles between 10 and $80^{\circ}$ with the purpose of establishing a crystalline phase of the samples. The average crystallite sizes were determined by the Scherrer equation [14]:

$\mathrm{D}=\frac{0.9 \lambda}{\beta \cos \theta}$

where $\lambda$ is the $X$-ray wavelength, $\beta$ is the peak width at half maximum, and $\theta$ is the Bragg angle. The percentages of rutile and anatase in the powder were calculated by the following equation developed by Spurr et al. $[14,15]$

Rutile (\%) $=\frac{1}{1+0.79\left(\frac{I_{R}}{I_{A}}\right)} \times 100$

where $I_{A}$ and $I_{R}$ are the integrated peak intensities of the most intense peaks for anatase [101] and rutile [110] peaks, respectively.

The surface morphology and agglomeration rate of the catalysts was investigated by the SEM JOEL JSM6460LV scanning electron microscope. In order to achieve conductivity, the sample preparation for imaging was carried out by coating them with the layer of gold. Operating conditions in SEM imaging were: acceleration voltage $25 \mathrm{kV}, 30 \mathrm{~mA}$ current at a working distance of $50 \mathrm{~mm}$ during $180 \mathrm{~s}$. Magnifications were applied in the range of 10 to $200.000 \mathrm{x}$.

\section{Photocatalytic activity}

In order to test the photo-catalytic activity of the catalysts, a decomposition/decolorization of Methylene blue dye (MB) was tested under illumination of UV lamp (Roth Co., $16 \mathrm{~W}, 25 \mathrm{~mW} / \mathrm{cm}^{2}$ ) (with the maximum emission at the wavelength $366 \mathrm{~nm}$ ). The UV lamp was located at a distance of $10 \mathrm{~cm}$ from the reaction solution, which was magnetically stirred during the experiments with a constant speed.

Prior to the UV illumination, catalysts were mixed with MB test-solution at constant stirring during 24 hours in dark in order to establish the adsorption-desorption equilibrium of the dye molecules onto the catalysts surface. The decolorisation/decomposition process was monitored by measuring the absorption spectrum of the MB solution after the phase separation using UV/Vis spectrophotometer (Schimadzu Co.) and following the maximum absorbance at $\lambda_{\max }=664 \mathrm{~nm}$. At previously specified time-intervals, aliquots were taken out from the solution and then centrifuged and filtrated prior to measuring. The performed photocatalytic experiments took place at the original/natural $\mathrm{pH}$ value of the MB solution $(\mathrm{pH} 6.8-7.1)$.

Photocatalytic efficiency of the prepared titania powders were determined by using the following equation (3):

$\%$ dye degradation $=\frac{\mathrm{C}_{0}-\mathrm{C}_{\mathrm{t}}}{\mathrm{C}_{0}} \times 100$.

where $C_{0}$ is the initial concentration of the MB dye solution and $\mathrm{C}_{t}$ is the concentration of the dye solution at a specific time interval.

\section{Results and discussion}

\section{Catalysts characterization}

Textural properties

The textural properties measured for the synthesized $\mathrm{TiO}_{2}$-based catalysts are presented in Table 1 . It can be noted that different alkalinity of the precursor solution has a great influence on the specific surface area, mean pore diameter and pore volume of the prepared $\mathrm{TiO}_{2}$-based catalytic materials. With the increase of $\mathrm{pH}$ from 10 to 13, the BET surface area decreases significantly, while the mean pore diameter increases. Mean pore diameter measurements for both catalytic samples showed that the total surface area is mainly characterized with mesopores. The pore volume decreased to 
$0.032 \mathrm{~cm}^{3} / \mathrm{g}$ when high alkali conditions of the synthesis process were applied.

The observed changes in textural properties had a substantial influence on the photocatalytic efficiency of the synthesized catalytic samples. According to the research previously reported [16], the increased catalytic activity can be expected with the use of catalysts that have larger specific surface areas. Moreover, a larger pore volume can make the process of pollutants diffusion to catalytically active sites easier, and thus increase the rate of photocatalytic decolorisation/degradation. The authors suggest that better/superior photocatalytic performance of the TA10 sample compared to TA13 could be due to more favorable textural properties of the titania-based material prepared at lower $\mathrm{pH}$ (larger BET surface area, larger pore volume, and acceptable mean pore diameter) (Figure 3).

Table 1. Textural parameters of titania-based catalysts

\begin{tabular}{cccc}
\hline Catalysts & $\begin{array}{c}\text { Surface area } \\
\mathbf{S}_{\mathrm{BET}}\left(\mathbf{m}^{\mathbf{2}} \mathbf{g}^{-1}\right)\end{array}$ & $\begin{array}{c}\text { Mean pore } \\
\text { diameter }(\mathbf{n m})\end{array}$ & $\begin{array}{c}\text { Pore volume } \\
\left(\mathbf{c m}^{\mathbf{3}} \mathbf{g}^{-1}\right)\end{array}$ \\
\hline TA10 & 34.3 & 8.3 & 0.075 \\
TA13 & 9.2 & 15.8 & 0.032 \\
\hline
\end{tabular}

\section{Structural properties}

The X-ray diffractograms of the prepared nano-powders are shown in Figure 1. All registered peaks for both synthesized samples calcined at $450{ }^{\circ} \mathrm{C}\left(2 \theta \sim 25.5^{\circ}\right.$, $37.1^{\circ} ; 38.0^{\circ} ; 38.7^{\circ} ; 48.2^{\circ} ; 54.1^{\circ} ; 55.3^{\circ} ; 62.9^{\circ} ; 69.0^{\circ}$; $70.5^{\circ}$ for TA10; $2 \theta \sim 24.7^{\circ}$ and $47.9^{\circ}$ for TA13) correspond to well-known diffraction peaks of the anatase crystal phase $[17,18,19]$. In both catalytic samples, a rutile crystal phase was not observed. It is noticeable that peaks were sharper, stronger and characterized better crystallinity when lower $\mathrm{pH}$ was applied during the titania powder preparation (TA10). The average crystallite sizes of $\mathrm{TiO}_{2}$-based samples calculated by Scherrer's equation were around 20 and $16 \mathrm{~nm}$ for TA10 and TA13, respectively (Table 2.).

Table 2. XRD results of titania-based catalysts samples

\begin{tabular}{ccccc}
\hline Catalysts & $\mathbf{d}_{\mathrm{A}}(\mathrm{nm})$ & $\mathbf{d}_{\mathrm{R}}(\mathrm{nm})$ & $\mathbf{W}_{\mathrm{A}}(\%)$ & $\mathbf{W}_{\mathrm{R}}(\%)$ \\
\hline TA10 & 20.06 & $/$ & 100 & $/$ \\
TA13 & 16.27 & $/$ & 100 & $/$ \\
\hline
\end{tabular}

The authors suppose that the obtained superior photocatalytic activity for the TA10 compared to the TA13 catalytic material (Figure 3 ) is the result of the favorable crystalline structure of the catalytically active anatase phase and the appropriate crystallite size, along with other catalytic properties.

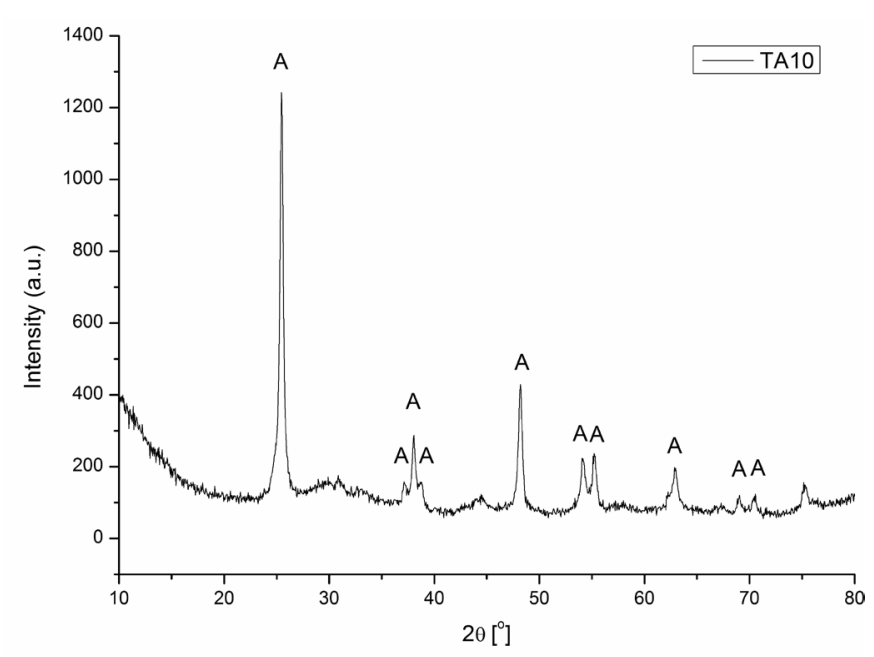

(a)

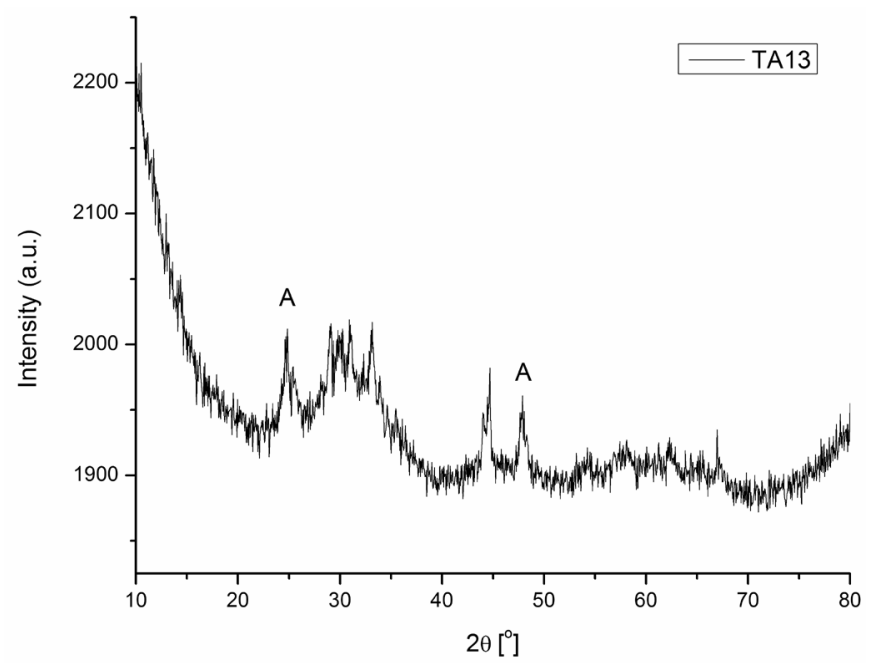

(b)

Figure 1. XRD patterns of the a) TA10 and b) TA13 samples

\section{Morphological properties}

The surface morphology of the prepared TiO2-based catalytic samples was investigated by the use of the SEM technique (Figure 2). The SEM images reveal typical spherical structures (shaped particles) with the relatively smooth surface for both catalytic samples. When TA10 sample was observed, this spherical structure consisted of mainly uniform primary particles up to $100 \mathrm{~nm}$ in size. However, when highly alkali $\mathrm{pH}$ value was applied during the synthesis process (TA13), the particles tended to agglomerate forming secondary particles that were significantly larger in size compared to primary particles of the TA10 titania catalytic sample.

Differences in morphology and porosity of these catalytic systems had influence on their final photocatalytic efficiency. 


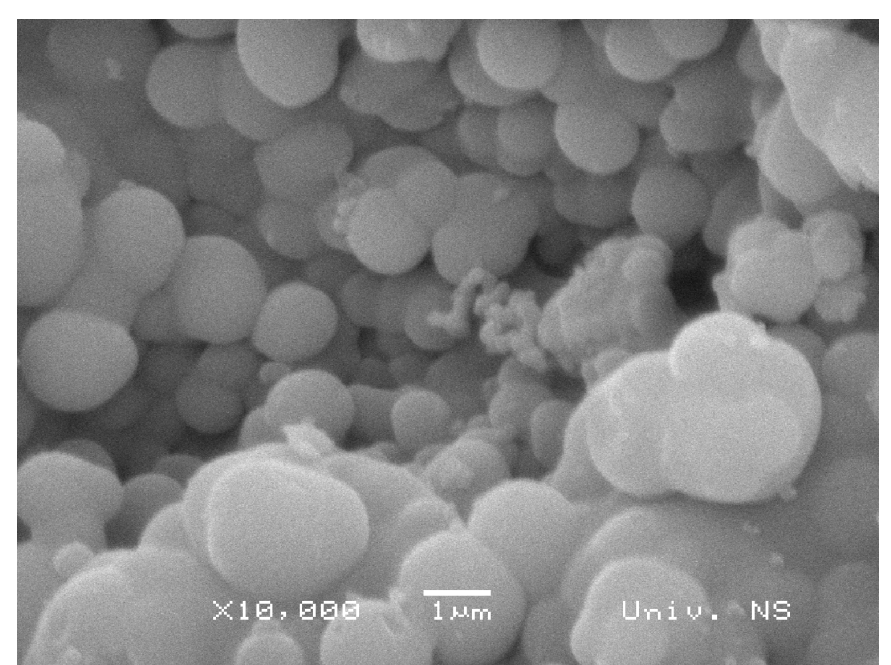

(a)

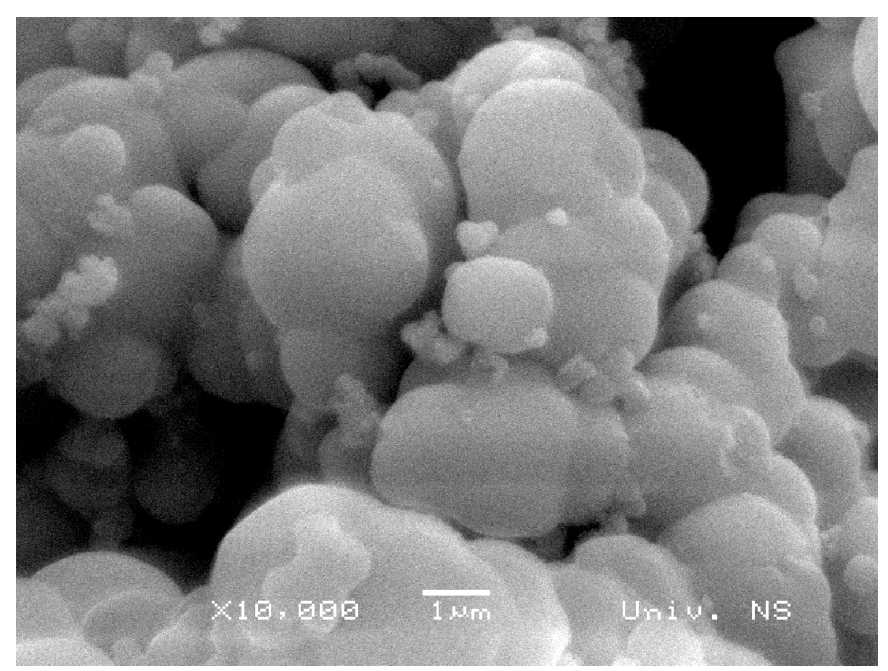

(b)

Figure 2. SEM micrographs of catalytic samples a) TA10 and b) TA13

The photocatalytic activity

Influence of different $\mathrm{pH}$ used in the catalysts preparation procedures

The photocatalytic-test experiment was run under the same experimental conditions for both catalytic samples during 24 hours. Photocatalytic activities of the prepared catalysts (TA10 and TA13) are shown in Figure 3 When TA10 sample was used, almost total MB decolorisation/ degradation (around 98\%) was registered under relatively mild experimental conditions (relatively low energy of UV illumination and original $\mathrm{pH}$ of the MB solution) after about 20 hours. However, the degradation efficiency was found to be reduced to around $61 \%$ after about $20 \mathrm{~h}$, when TA13 was used in the photocatalytic process. This behavior can be explained by the fact that the catalyst synthesized at $\mathrm{pH} 10$ has a larger BET surface area, better crystallinity and morphological properties compared to the catalyst prepared at $\mathrm{pH} 13$. Moreover, a sufficiently large pore volume in the case of TA10 catalytic sample can support an easier transfer of the MB dye molecules (reactants) to catalytically active sites and the diffusion of the products from the catalytically active sites.

vThe above-mentioned results clearly indicate that $\mathrm{pH}$ values of the precursor solutions have a significant influence on the physico-chemical properties of the $\mathrm{TiO}_{2}-$ based catalytic materials, and their final photocatalytic performance in the reaction of MB dye decolorisation/ degradation.

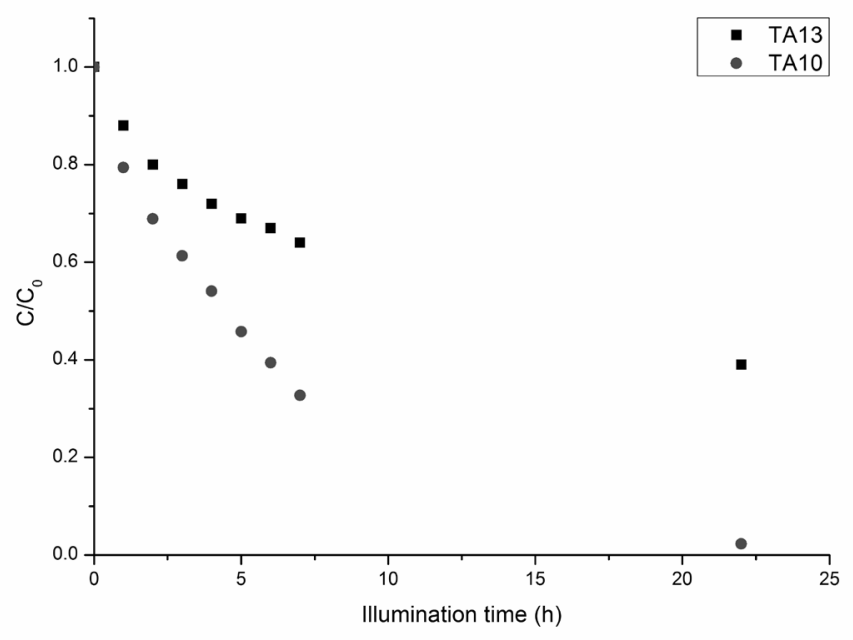

Figure 3. Comparisons of the degradation rate for the decomposition of Methylene blue dye under TA10 and TA13 catalytic samples (experimental conditions: catalyst amounts $0.05 \mathrm{~g}$, the initial dye concentration $0.01 \mathrm{mmol} / \mathrm{dm} 3, \mathrm{pH}=6.8$ to 7.1 )

Influence of initial concentrations of the MB dye

The selected experiments were conducted at three different initial dye concentrations, with constant weights of the catalyst sample TA10 (50 mg), neutral $\mathrm{pH}$, and at constant reaction-time intervals. Figure 4 shows that a decomposition of $\mathrm{MB}$ decreased with increasing the initial concentration of the dye from $5 \cdot 10^{-3}$ to $10 \cdot 10^{-3}$ $\mathrm{mmol} / \mathrm{dm}^{3}$. An assumption can be made that when the initial dye concentration is lower, the optical density of the MB solution is lower as well, thus the UV light can easily reach the $\mathrm{TiO}_{2}$ surface and, therefore the photonic efficiency is greater. On the contrary, with increasing the initial dye concentration, UV light can penetrate more difficulty through the MB solution due to higher optical density, resulting in a lower photo-catalytic degradation rate. Furthermore, the formation of hydroxyl radicals is suppressed when a large amount of dye is adsorbed on the catalyst surface, because the active sites on the catalyst surface are covered by dye molecules. 


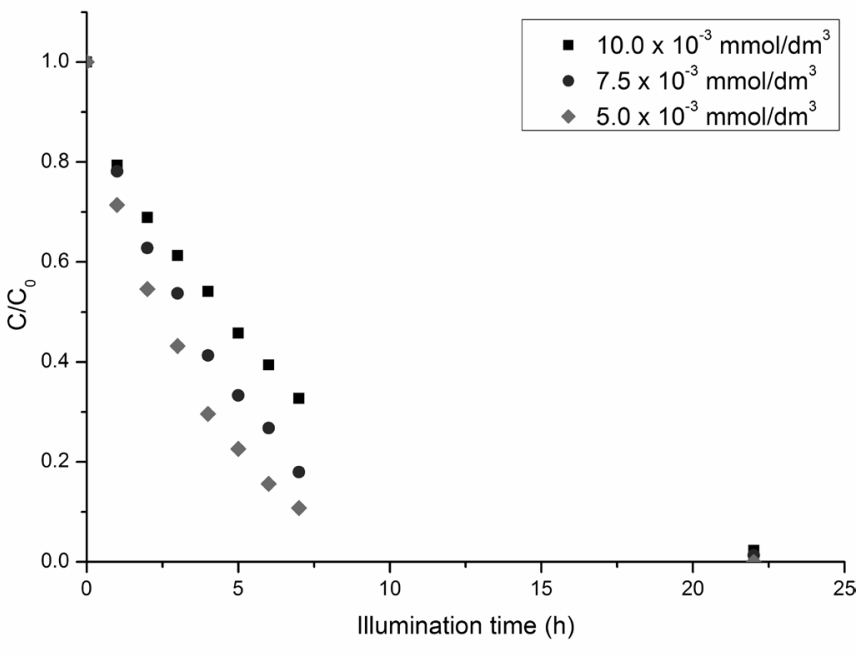

Figure 4. The influence of the initial dye concentration on the photodegradation rate for the decomposition of Methylene blue by using $\mathrm{TiO}_{2}$-based catalytic material (TA10) (experimental conditions: catalyst amounts $0.05 \mathrm{~g}, \mathrm{pH}=6.8$ to 7.1 )

\section{Conclusions}

In the scope of this study, two types of nanostructured catalysts were synthesized via modified sol-gel method at two selected $\mathrm{pH}$ values. The prepared photocatalytic activity of the samples was tested for degradation/decolorisation of methylene blue dye under relatively mild experimental conditions.

By summarizing the obtained results of the photocatalytic titania-based materials, it can be concluded that the applied $\mathrm{pH}$ values during the synthesis procedure can greatly affect physico-chemical properties that had a major impact on the photocatalytic activity.

When the TA10 sample was used in photocatalytic test, the degradation rate was higher compared to TA13. This improved catalytic efficiency of TA10 can be correlated with better physico-chemical properties compared with TA13 (larger specific surface area, better crystallinity, larger pore volume and better homogeneity of the material). However, highly alkali conditions resulted in diminishing specific surface area of the titania-based catalyst, as well as lower crystallinity and the formation of rather secondary agglomerates instead of primary particles in the nano-scale range.

The effect of the initial MB concentration was also tested with the use of the TA10 catalyst sample. The obtained results indicated that degradation/decolorisation rate was higher when the initial concentration of the dye solution was lower due to lower optical density and greater photonic efficiency.

\section{Acknowledgments}

The authors wish to thank the Ministry of Education, Science and Technological Development of the Republic of Serbia (Project OI 1612008) for a financial support.

\section{References}

[1] P. Mohapatra, K. M. Parida, Photocatalytic activity of sulfate modified titania 3: Decolorization of methylene blue in aqueous solution, Journal of Molecular Catalysis A: Chemical, 258 (2006) $118-123$.

[2] A. Franco, M. C. Neves, M. M. L. R. Carrott, M. H. Mendonca, M. I. Pereira, O. C. Monteiro, Photocatalytic decolorization of methylene blue in the presence of $\mathrm{TiO}_{2} /$ ZnS nanocomposites, Journal of Hazardous Materials, 161 (2009) $545-550$.

[3] K. G. Bhattacharyya, A. Sharma, Kinetics and thermodynamics of Methylene Blue adsorption on Neem (Azadirachta indica) leaf powder, Dyes and Pigments, 65 (2005) $51-59$

[4] S. H. S. Chan, T. Y. Wu, J. C. Juan, Chee Yang Teh, Recent developments of metal oxide semiconductors as photocatalysts in advanced oxidation processes (AOPs) for treatment of dye waste-water, Journal of Chemical Technology and Biotechnology, 86 (2011) 1130 - 1158.

[5] F. Han, V. S. R. Kambala, M. Srinivasan, D. Rajarathnam, R. Naidu, Tailored titanium dioxide photocatalysts for the degradation of organic dyes in wastewater treatment: $A$ review, Applied Catalysis A: General, 359 (2009) 25 - 40.

[6] A. C. Affam, M. Chaudhuri, Degradation of pesticides chlorpyrifos, cypermethrin and chlorothalonil in aqueous solution by $\mathrm{TiO}_{2}$ photocatalysis, Journal of Environmental Management, 130 (2013) 160 - 165.

[7] N. M. Makwana, C. J. Tighe, R. I. Gruar, P. F. McMillan, J. A. Darr, Pilot plant scale continuous hydrothermal synthesis of nano-titania; effect of size on photocatalytic activity, Materials Science in Semiconductor Processing, 42 (2016) 131 - 137.

[8] M. Imran, S. Riaz, S. Naseem, Synthesis and characterization of titania nanoparticles by sol-gel technique, Materials Today: Proceedings, 2 ( 2015 ) 5455 $-5461$.

[9] C.-S. Kim, B. K. Moon, J.-H. Park, S. T. Chung, S.-M. Son, Synthesis of nanocrystalline $\mathrm{TiO}_{2}$ in toluene by a solvothermal route, Journal of Crystal Growth, 254 (2003) $405-410$.

[10] J. H. Lee, Y. S. Yang, Effect of hydrolysis conditions on morphology and phase content in the crystalline $\mathrm{TiO}_{2}$ nanoparticles synthesized from aqueous $\mathrm{TiCl}_{4}$ solution by precipitation, Materials Chemistry and Physics, 93 (2005) $237-242$.

[11] S. Ahmed, M. G. Rasul, W. N. Martens, R. Brown, M. A. Hashib, Advances in Heterogeneous Photocatalytic Degradation of Phenols and Dyes in Wastewater: A Review, Water Air and Soil Pollution, 215 (2011) 3 - 29.

[12] S. Ahmed, M.G. Rasul, R. Brown, M.A. Hashib, Influence of parameters on the heterogeneous photocatalytic degradation of pesticides and phenolic contaminants in wastewater: A short review, Journal of Environmental Management, 92 (2011) $311-330$.

[13] S. Senthilkumaar, K. Porkodi, R. Gomathi, A. Geetha Maheswari, N. Manonmani, Sol-gel derived silver doped nanocrystalline titania catalyzed photodegradation of methylene blue from aqueous solution, Dyes and Pigments, 69 (2006) $22-30$.

[14] S. Buddee, S. Wongnawa, P. Sriprang, C. Sriwong, Curcumin-sensitized $\mathrm{TiO}_{2}$ for enhanced photodegradation of dyes under visible light, Journal of Nanoparticle Research, 16 (2014) 2336 - 2357. 
[15] R. Spurr and H. Myers, Quantitative analysis of anataserutile mixtures with an X-ray diffractometer, Analytical Chemistry, 29 (1957) $760-761$.

[16] F. He, F. Ma, J. Li, T. Li, G. Li, Effect of calcination temperature on the structural properties and photocatalytic activities of solvothermal synthesized $\mathrm{TiO}_{2}$ hollow nanoparticles, Ceramics International, 40 (2014) $6441-6446$.

[17] M. Koelsch, S. Cassaignon, J. F. Guillemoles, J. P. Jolivet, Comparison of optical and electrochemical properties of anatase and brookite $\mathrm{TiO}_{2}$ synthesized by the sol-gel method, Thin Solid Films, 403-404 (2002) 312 - 319.
[18] R. Miao, Z. Luo, W. Zhong, S.-Y. Chen, T. Jiang, B. Dutta, Y Nasr, Y. Zhang, S. L. Suib, Mesoporous $\mathrm{TiO}_{2}$ modified with carbon quantum dots as ahigh-performance visible light photocatalyst, Applied Catalysis B: Environmental, 189 (2016) $26-38$.

[19] M. H. Habibi, M. N. Esfahani, T. A. Egerton, Photochemical Characterization and Photocatalytic Properties of a Nanostructure Composite $\mathrm{TiO}_{2}$ Film, International Journal of Photoenergy, Article ID 13653, (2007) doi:10.1155/2007/13653

\section{DEKOLORIZACIJA METILEN PLAVO BOJE NA KATALIZATORU NA BAZI $\mathrm{TIO}_{2}$ : UTICAJ RAZLIČITIH PH VREDNOSTI PRIMENJENIH U PROCESU PRIPREME KATALIZATORA}

Marija B. Vasić, Aleksandra R. Zarubica

Univerzitet u Nišu, Prirodno matematički fakultet, Departman za Hemiju, Niš, Srbija

$\mathrm{U}$ ovom radu, nanoprah katalizatori na bazi $\mathrm{TiO}_{2}$ sintetisani su modifikovanom sol-gel metodom. Ispitivan je uticaj pH vrednosti rastvora prekursora tokom procesa sinteze na teksturalna, strukturalna i morfoloska svojstva sintetisanih katalizatora. Fotokatalitička aktivnost pripremljenih TiO2 katalizatora testirana je pomoću reakcije dekolorizacije/razgradnje metilen plavo (MP) boje kao model polutanta pod dejstvom UV-A zračenja. Pored toga, sa ciljem optimizacije fotokatalitičkog procesa, ispitivan je i uticaj inicijalne koncentracije MP boje uz korišćenje katalizatora sintetisanog na $\mathrm{pH} 10$. Na osnovu dobijenih rezultata, uočava se da je katalizator pripremljen na pH 10 pokazao veći efekat na dekolorizaciju boje u poredjenju sa katalizatorom koji je pripremljen na pH 13. Finalna fotokatalitička aktivnost dovedena je u korelaciju sa fizičko-hemijskim svojstvima sintetisanih katalizatora.
(ORIGINALNI NAUČNI RAD) UDK 549.514:66.097:667.289

Ključne reči: Metilen plavo, Nanoprah pH vrednost, Sol-gel, Titian(IV)-oksid 